\title{
Prognostic value of different staging systems in neuroblastomas and completeness of tumour excision
}

\author{
N L T CARLSEN, I J CHRISTENSEN, H SCHROEDER, P V BRO, U HESSELBJERG, K B JENSEN, \\ AND O H NIELSEN
}

State University Hospital, Rigshospitalet, and Finsen Laboratory, Copenhagen, University Hospital, Aarhus, University Hospital, Odense, and Aalborg Hospital, Denmark

SUMmaRY Two hundred and fifty three patients were retrospectively assigned to eight different staging systems proposed for neuroblastomas, and the prognostic value of each staging system was evaluated individually. The ability of each system to predict prognosis was compared with the others and the system proposed by Evans et al found to be the best predictor, even better than the recently proposed Tumour-Nodes-Metastases staging system. This is probably due to the fact that factors other than the resectability of the tumour play a major role in the survival of these children. Age was found to have independent prognostic significance whatever staging system was used.

The vagaries of the natural history of neuroblastomas are notorious, and because of this various staging systems have been proposed in estimating the prognosis for children with this tumour, mostly based on the extent of the disease, the surgical resectability, the pattern of metastatic spread, and, in some cases, the degree of histologic differentiation. The staging system of Evans et $\mathrm{ll}^{1}$ is the most widely adopted, although the system proposed by Pinkel et $a l^{2} 3$ is also widely used and recently a Tumour-Nodes-Metastases (TNM) staging system has been devised under the auspices of the International Union against Cancer. ${ }^{4}$

The aims of this study were to restage retrospectively an unselected patient population comprising all children with neuroblastoma in Denmark during the period 1943-80 according to the various staging systems proposed, to compare the prognostic value of the different systems, and to evaluate the role of surgical excision of the primary tumour on the prognosis.

\section{Material and methods}

The patients comprised 255 cases of neuroblastoma treated in Denmark during the period 1943-80. Of these, 237 had been proved histologically. In the remaining 18 the case history pointed clearly to neuroblastoma but either the histological diagnosis was inconclusive- that is, suggestive of neuroblastoma-and could not be re-examined (13 cases) or no histological diagnosis had been made and the diagnosis was based on either raised urinary excretion of 3-methoxy-4-hydroxymandelic acid (three cases) or orbital metastases and tumour abdominis (two cases). These 18 cases were staged according to Evans et al $^{1}$ as follows: stage I: 0 cases; stage II: two; stage III: two; stage IV: 12; stage IV-S: one; stage unknown: one, as the hospital record of a child with the histological diagnosis suggestive of neuroblastoma had disappeared. One child died at home without having been admitted to hospital and thus could not be staged; the autopsy revealed neuroblastoma. It was therefore possible to stage the extent of the disease according to the various staging systems for 253 cases only. Studies from part of this patient population have been published elsewhere. ${ }^{5}$

Patients without evidence of the disease two years after diagnosis were considered cured. The tumours were staged retrospectively according to the following systems: Evans et al, ${ }^{16}$ Pinkel et al, ${ }^{2}{ }^{3}$ Sandstedt et al ${ }^{7}$ Cohen, ${ }^{8}$ James, ${ }^{9}$ Thurman and Donaldson, ${ }^{10}$ the TNM clinical stage grouping, ${ }^{4}$ and the TNM post surgical histopathological stage grouping. ${ }^{4}$ It should be mentioned that for staging purposes investigations not performed were considered negative. The different staging systems are as follows.

Evans et al. 16

Stage I

Tumours confined to the organ or structure of origin. 


\section{Stage II}

Tumours extending in continuity beyond the organ or structure of origin but not crossing the midline. (Regional lymph nodes on the homolateral side may be involved. All intraspinal tumours are included unless the extraspinal portion of the tumour crossed the midline. For tumours arising in midline structures-for example, the organs of Zuckerkandlpenetration beyond the capsule and involvement of lymph nodes on the same side shall be considered stage II. Bilateral extension of any sort shall be considered stage III.)

Stage III

Tumours extending in continuity beyond the midline. (Regional nodes bilaterally may be involved.) Stage IV

Remote disease involving skeleton, organs, soft tissues, or distant lymph node groups (see stage IV-S).

Stage IV-S

Patients who would otherwise be classed as stage I or II but who have remote disease confined only to one or more of the liver, skin, or bone marrow (without radiographic evidence of bone metastases on complete skeletal survey).

\section{Pinkel et al. ${ }^{2} 3$}

\section{Stage I}

Localised, complete resected tumour.

Stage IIA

Localised, resected, but possibly residual microscopic tumour.

Stage IIB

Localised tumour, partially or not resected.

Stage IIIA

Regional or systemic spread of disease without involvement of bone or bone marrow.

Stage IIIB

Same as stage IIIA, but evidence of a single, localised destructive lesion of bone; no involvement of bone marrow.

Stage IIIC

Generalised tumour in bone or bone marrow, or both.

\section{Sandstedt et al. ${ }^{7}$}

Stage $A$

Localised, well incapsulated tumour.

Stage $B$

Tumours infiltrating surrounding organs or regional lymph nodes.

Stage $C$

Tumours with metastases to distant lymph nodes or other organs, or both.
Stage IV-S

The same definition as in the classification of Evans et al (see above).

\section{Cohen. ${ }^{8}$ \\ Stage 1}

Disseminated disease. Cases showing histological evidence of involvement of bone marrow or clinical or radiological evidence of bony or periorbital metastases.

Stage 2

Hepatic disease. Cases presenting with gross hepatomegaly without other evidence of metastatic involvement, with or without a discoverable primary tumour. Liver biopsy confirms that the liver is diffusely involved by undifferentiated neuroblastoma.

Stage 3

Peripheral disease. These cases present with superficial nodules, which are shown on biopsy examination to be undifferentiated neuroblastoma tissue. A primary tumour may or may not be detectable. Fresh nodules continue to occur for a limited time and may be cutaneous, subcutaneous, or subfascial, within one of the muscle bellies. They are usually small, encapsulated nodules that are readily dissected out for biopsy examination.

Stage 4

Infiltrative disease. In these cases the tumour is usually large and vascular. Because of its lack of a complete capsule it is invariably irremovable. There is usually pronounced involvement of regional lymph nodes, extending well up around the great vessels.

\section{Stage 5}

Encapsulated tumours. Such tumours can always be totally or subtotally removed.

Stage 6 and Stage 7

These comprise differentiated tumours (grade I or II of Beckwith and Martin ${ }^{11}$ ) and neuroblastoma in situ $^{12}$ but are excluded from this study as no attempt has been made to grade the tumours histologically in this study and as cases of neuroblastoma in situ possibly represent a variation in the normal morphogenesis of the adrenal gland. ${ }^{13}$

\footnotetext{
James. ${ }^{9}$

Stage $I$

Localised and resectable.

Stage II

Regional and unresectable.

Stage III

Generalised and without involvement of bone or marrow.
} 
Stage IV

Generalised and with involvement of bone or bone marrow.

Thurman and Donaldson. ${ }^{10}$ Excludes all children under 1 year of age.

Stage I

Localised and totally resectable.

Stage II

Regional, non-resectable.

Stage III

Generalised and with involvement of bone marrow.

Stage IV

Generalised and with involvement of bone.

Stages I and II are originally subclassified according to the differentiation of the tumours, which as previously mentioned is not possible in this study. Similarly, the original proposal that stage I tumours automatically be reclassified to stage II if excretion of catecholamine remains high three months after removal of the tumour is not possible for all tumours in this study as the urinary excretion of 3-methoxy-4hydroxymandelic acid was not analysed in all the patients. The proposal is therefore excluded from this study.

\section{TNM clinical stage grouping. ${ }^{4}$}

Stage I

Primary tumour $5 \mathrm{~cm}$ or less in its greatest dimension; no evidence of involvement of regional lymph nodes, or the minimum requirements to assess the regional lymph nodes cannot be met. No evidence of distant metastases.

Stage II

Primary tumour more than $5 \mathrm{~cm}$ but not more than $10 \mathrm{~cm}$ in its greatest dimension. No evidence of involvement of regional lymph nodes, or the minimum requirements to assess the regional lymph nodes cannot be met. No evidence of distant metastases.

Stage III

Primary tumour in stage I or II, but evidence of involvement of regional lymph node or primary tumour is more than $10 \mathrm{~cm}$ in its greatest dimension. The regional lymph nodes may or may not be involved. No evidence of distant metastases.

Stage IV

Primary tumour single, irrespective of its greatest dimension. Regional lymph nodes may or may not be involved. Evidence of distant metastases.

Stage $V$

Multicentric tumours occurring simultaneously. Regional lymph nodes may or may not be involved. Distant metastases may or may not be present.
TNM post surgical histopathological stage grouping. ${ }^{4}$ Stage I

Excision of tumour complete and margins histologically free. No evidence of tumour can be found on histological examination of regional lymph nodes or the extent of invasion cannot be assessed-that is, no surgical excision of the regional lymph nodes performed or inadequate information on the pathological findings. No evidence of distant metastases. Stage II

Excision of tumour complete and margins histologically free. Evidence of invasion of regional lymph nodes, involved nodes considered to be completely resected, or the extent of invasion cannot be assessed (see above). No evidence of distant metastases.

Stage IIIA

Evidence of microscopic residual tumour. No evidence of tumour found on histological examination of regional lymph nodes, or evidence of invasion of regional lymph nodes, involved nodes considered to be completely resected, or the extent of invasion cannot be assessed (see above). No evidence of distant metastases.

Stage IIIB

Evidence of macroscopic residual tumour or grossly incomplete excision or primary tumour. Regional lymph nodes may or may not be completely resected or excision of tumour complete or with evidence of microscopic residual tumour, but evidence of invasion of regional lymph nodes, involved nodes considered to be incompletely resected. No evidence of distant metastases.

Stage IV

Primary tumour may or may not be resected. Regional lymph nodes may or may not be involved (and completely or incompletely resected). Evidence of distant metastases.

Stage $V$

Evidence of multicentric tumour. Regional lymph nodes may or may not be involved. Distant metastases may or may not be present.

In the TNM post surgical histopathological stage grouping ${ }^{4}$ the operations performed on the primary tumour are defined as follows. pTO: No evidence of tumour found on histological examination of specimen. pT1: Excision of tumour complete and margins histologically free. pT3a: Evidence of microscopic residual tumour. pT3b: Evidence of macroscopic residual tumour. pT3c: Grossly incomplete excision. The prefix y to the above mentioned categories indicates secondary operation. Thus only pT1, ypT0, ypT1, pT3a, урT3a, pT3b, and урT3b could be assigned as tumour excision in evaluating the role of surgery in patients with neuroblastoma.

The tumours were classified in each staging 
system, one by one, by carefully reviewing the surgical notes of each patient as well as the physical examination and diagnostic studies at the time of diagnosis.

The initial statistical analysis of the 253 patients consisted of calculation of survival curves and simple statistics on these. The log rank test was used to compare survival curves drawn by the actuarian (decrement) method of Kaplan-Meier. Each of the staging systems was evaluated individually for prognostic significance and logistic regression analysis ${ }^{14}$ used to detect the effect of each staging in the different systems on the survival after adjustment for other prognostic factors (age at diagnosis and treatment).

\section{Results}

Figure 1 shows the survival curves in the different stages proposed by Evans et al. ${ }^{16}$ The prognosis gets progressively worse from stage I to stage IV with stage IV-S lying between them. The differences in survival between the different stages are significant $(\mathrm{p}=0 \cdot 0001)$.

Figure 2 shows the survival curves in the different stages proposed by Pinkel et al. ${ }^{23}$ The prognosis gets progressively worse from stage I to stage IIIA $(p=0.0001)$, whereas the prognosis for stages IIA and IIB and for stages IIIA, IIIB, and IIIC are not significantly different.

Figure 3 shows the survival curves in the different stages proposed by Sandstedt et al. ${ }^{7}$ The prognosis gets progressively worse from stages $A$ to $C$ with stage IV-S lying between them. The differences in survival between the different stages are significant $(p=0 \cdot 0001)$.

Figure 4 shows the survival curves in the different stages proposed by Cohen. ${ }^{8}$ The prognosis gets progressively better from stage 1 to 5 , with stages 2 and 3 lying between them. The difference between stage 1 , stages 2 and 3 , stage 4 , and stage 5 is significant $(p=0.0001)$, whereas the difference between stages 2 and 3 is not significant.

Figure 5 shows the survival curves in the different stages proposed by James. ${ }^{9}$ The prognosis gets progressively worse from stage I to stage III $(p=0.0001)$, whereas the difference between stages III and IV is not significant.

Figure 6 shows the survival curves in the different stages proposed by Thurman and Donaldson. ${ }^{10}$ The prognosis gets progressively worse from stage $I$ to stage III $(p=0.0001)$, whereas the difference between stages III and IV is not significant.

Figure 7 shows the survival curves in the different

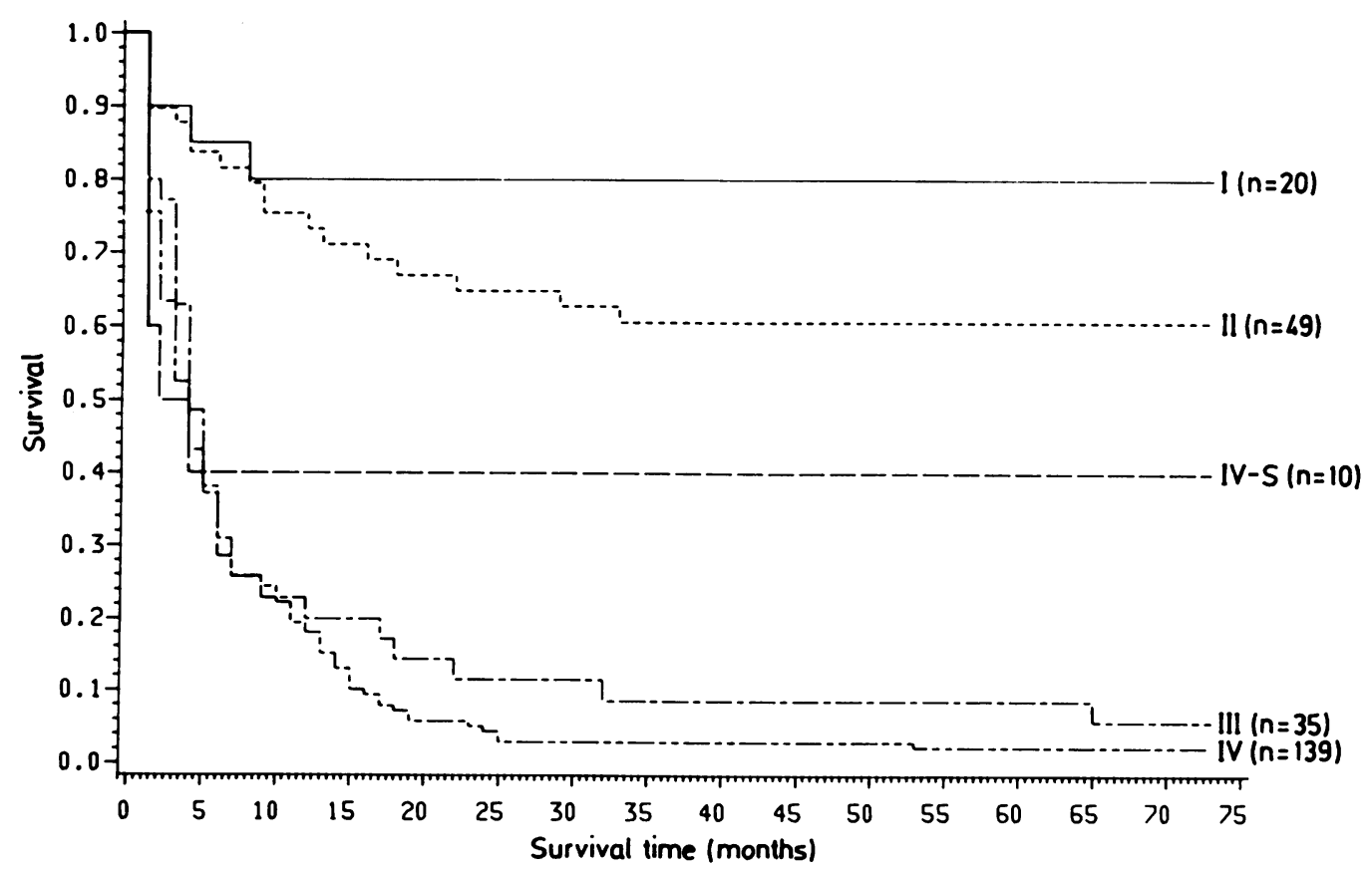

Fig. 1 Survival in the different stages as proposed by Evans et al by Kaplan-Meier plot (the decrement method). 
836 Carlsen, Christensen, Schroeder, Bro, Hesselbjerg, Jensen, and Nielsen

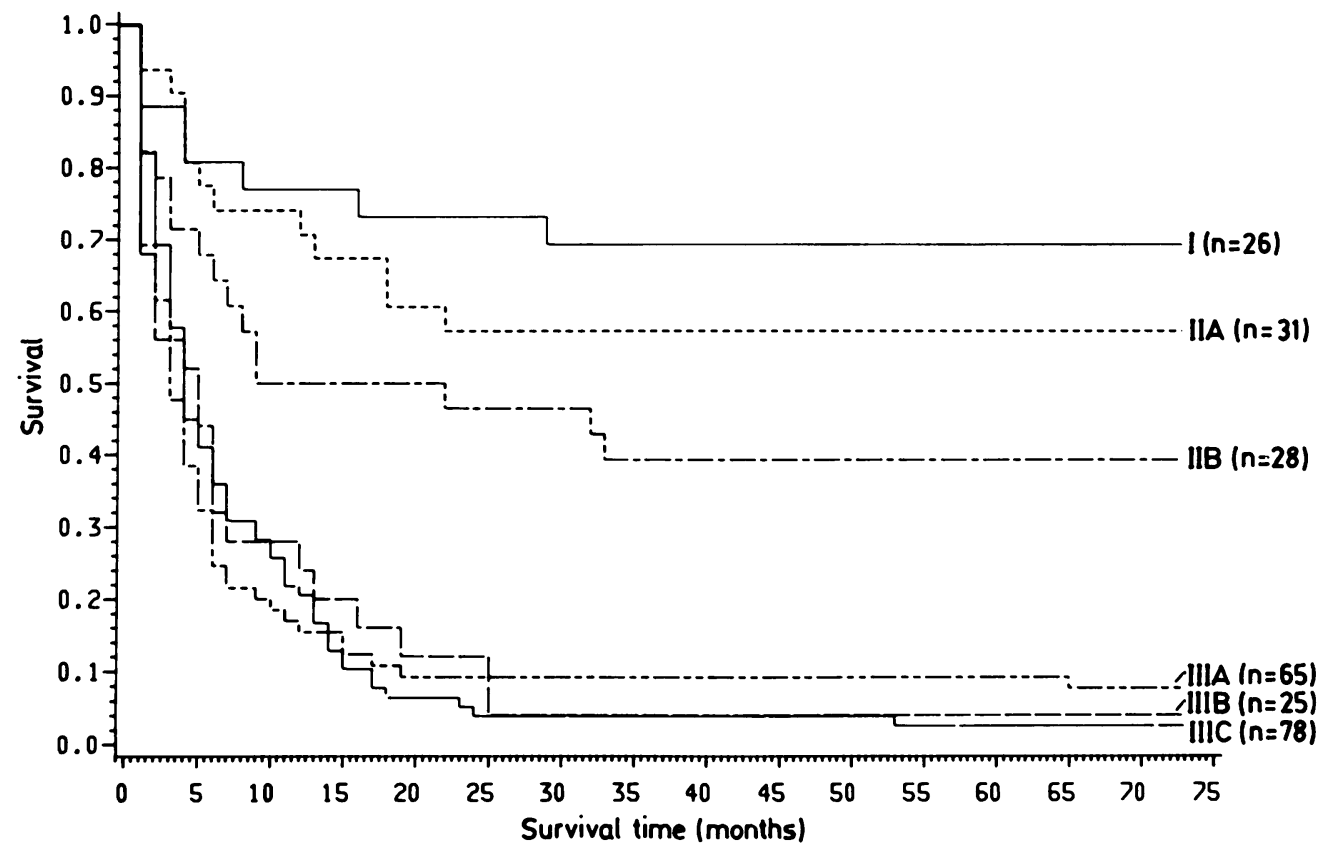

Fig. 2 Survival in the different stages as proposed by Pinkel et al by Kaplan-Meier plot (the decrement method).

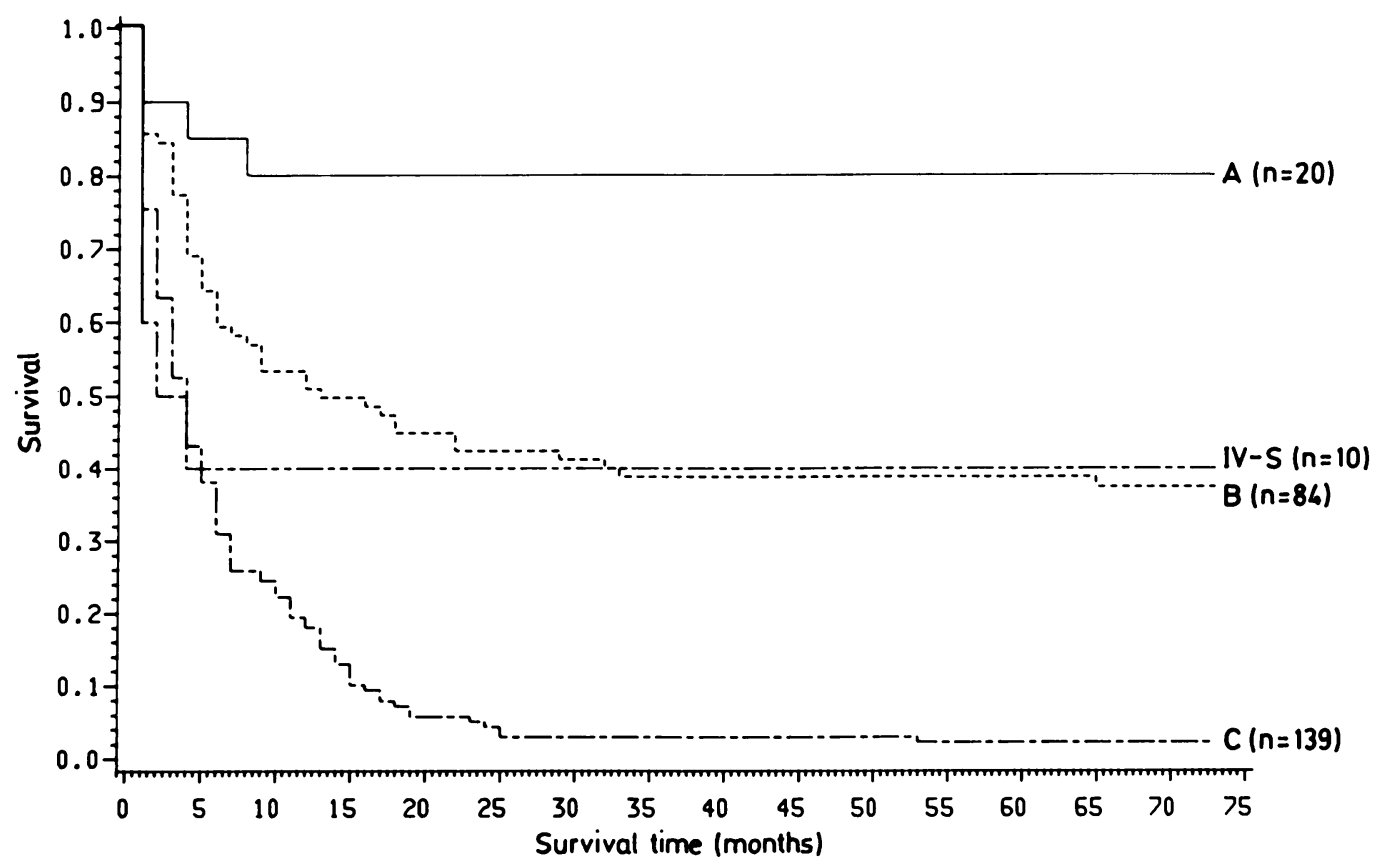

Fig. 3 Survival in the different stages as proposed by Sandstedt et al by Kaplan-Meier plot (the decrement method). 


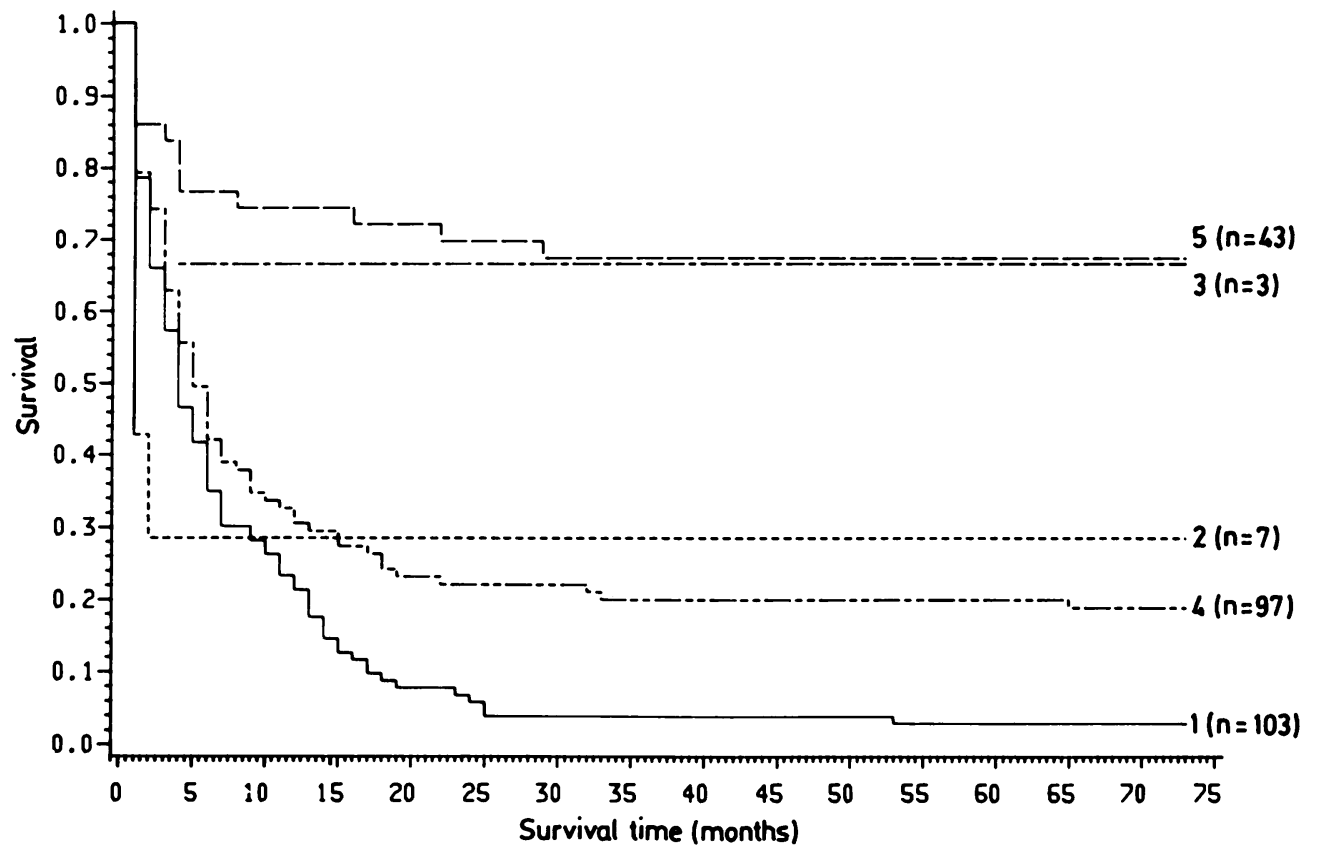

Fig. 4 Survival in the different stages as proposed by Cohen by Kaplan-Meier plot (the decrement method).

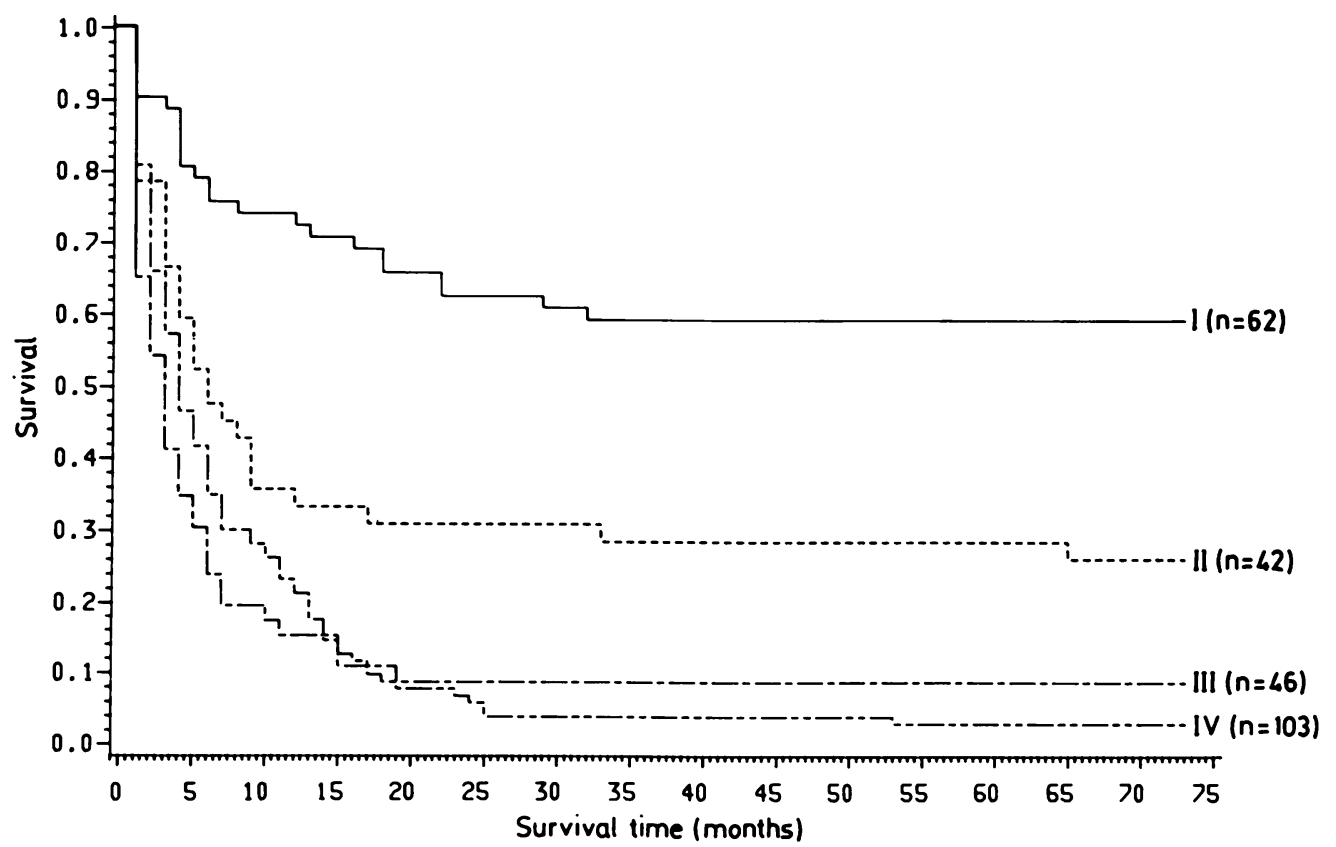

Fig. 5 Survival in the different stages as proposed by James by Kaplan-Meier plot (the decrement method). 
838 Carlsen, Christensen, Schroeder, Bro, Hesselbjerg, Jensen, and Nielsen

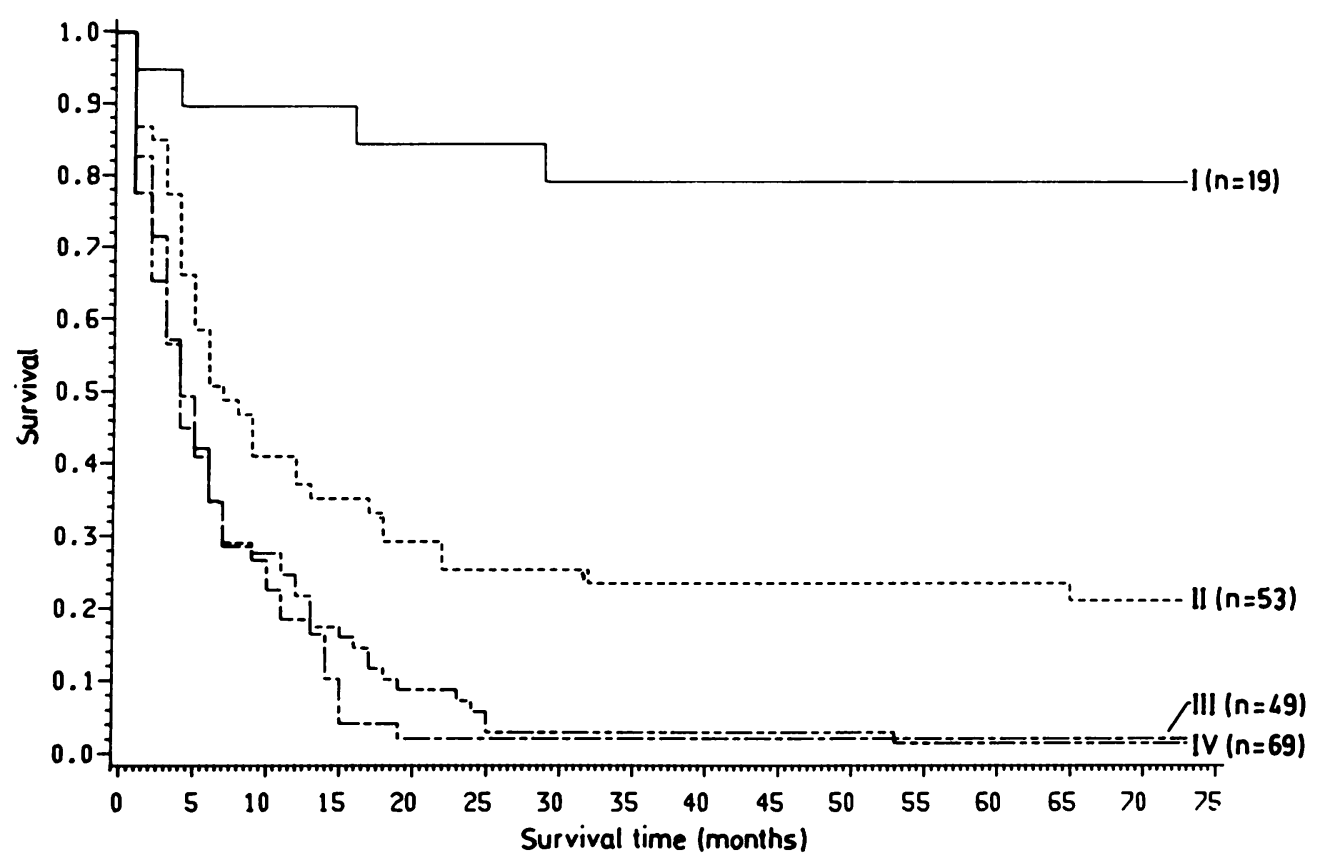

Fig. 6 Survival in the different stages as proposed by Thurman and Donaldson (excluding children aged under 1 year) by Kaplan-Meier plot (the decrement method).

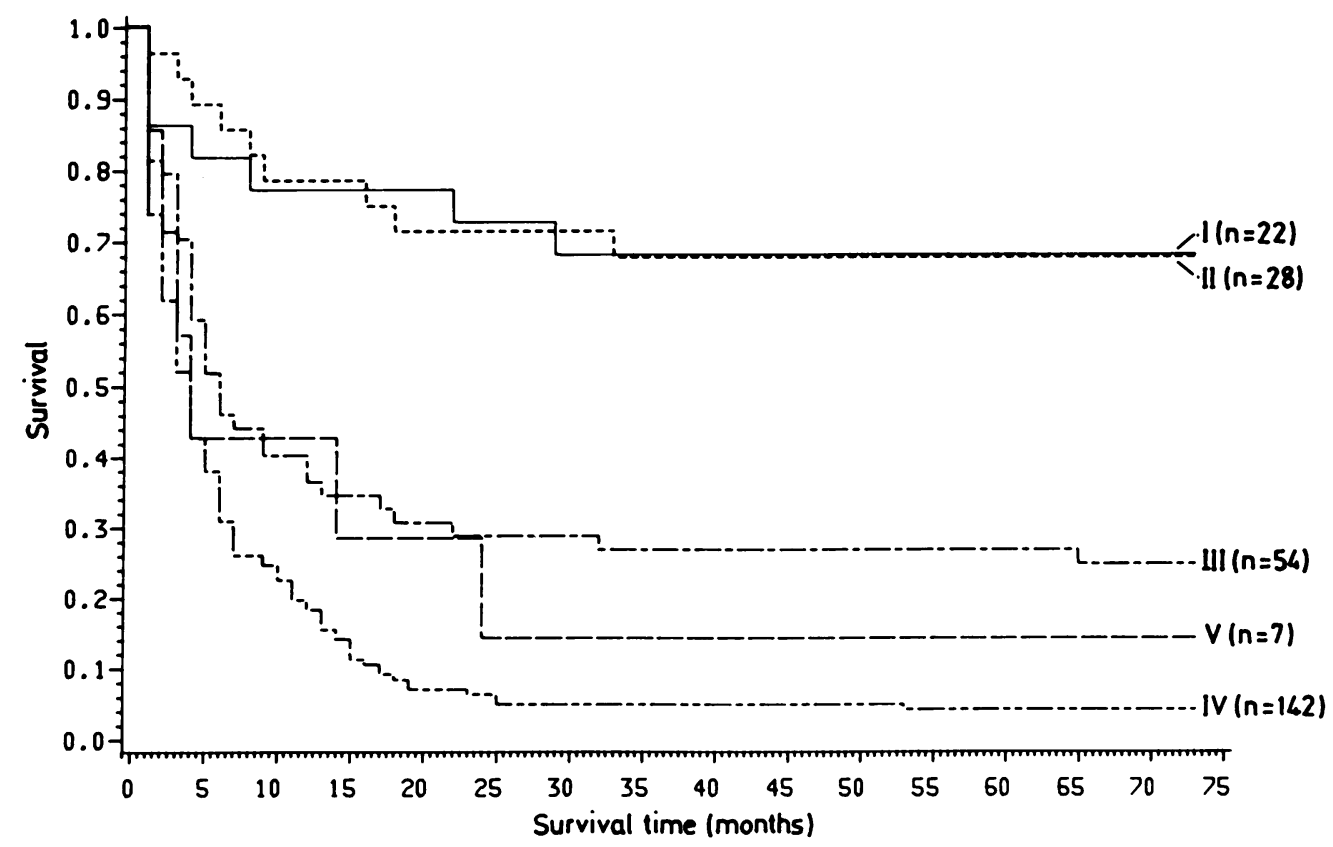

Fig. 7 Survival in the different stages of the TNM clinical stage grouping by Kaplan-Meier plot (the decrement method). 


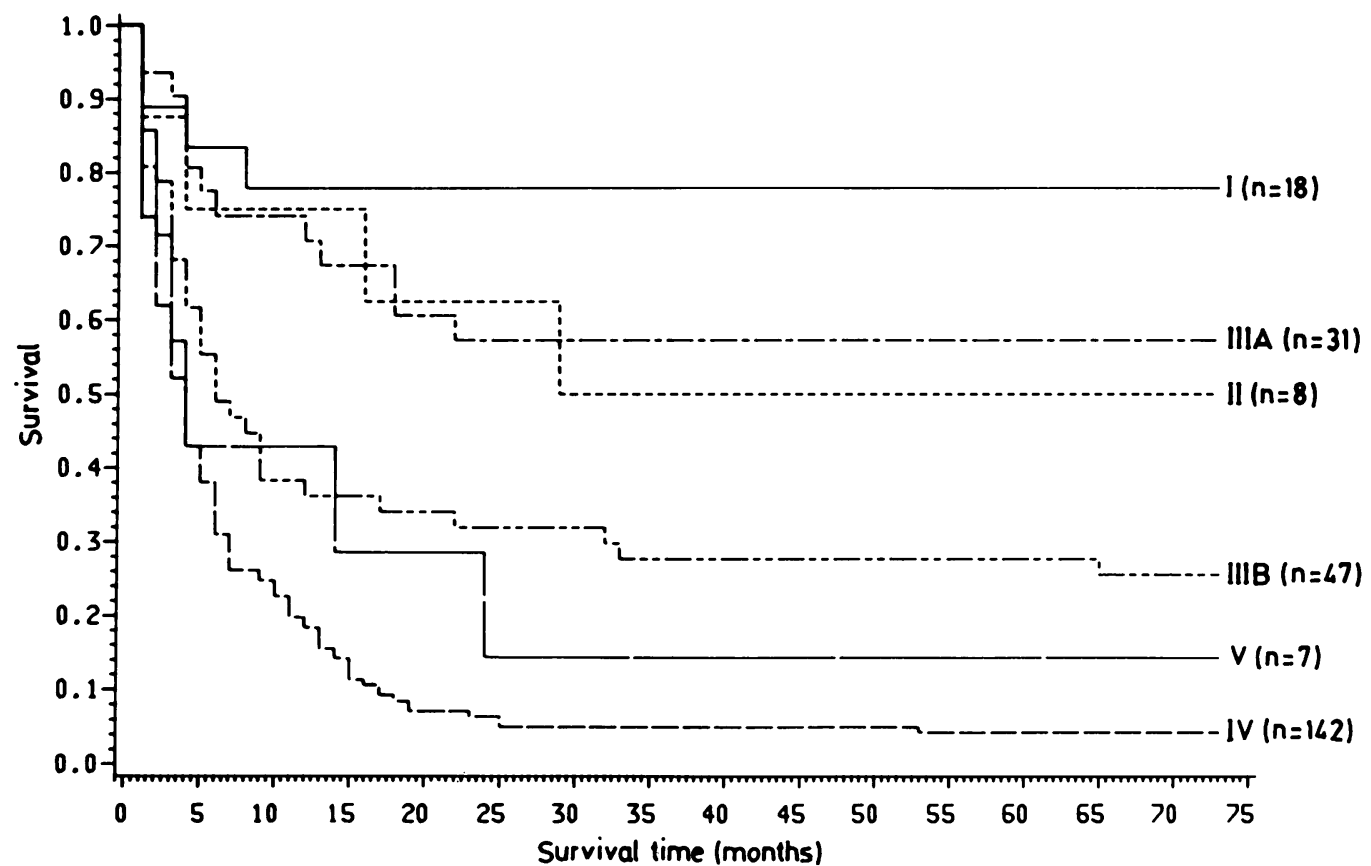

Fig. 8 Survival in the different stages of the TNM post surgical histopathological stage grouping by Kaplan-Meier plot (the decrement method).

stages of the TNM clinical stage grouping. ${ }^{4}$ The prognosis gets progessively worse from stage I to stage IV $(p=0.0001)$, whereas the differences between stages I and II and between stages IV and V are not significant.

Figure 8 shows the survival curves in the different stages of the TNM post surgical histopathological stage grouping. ${ }^{4}$ Again the prognosis becomes progressively worse from stage I to stage IV $(p=0.0001)$, whereas the differences between stages II and IIIA and between stages IV and V are not significant.

Comparison of the prognostic value of the different staging systems. Using the system of Evans $\mathrm{et} \mathrm{al}^{16}$ as reference stage for each patient, the distribution of the patients on the stages in the other systems is shown in the Table, which also gives the number of survivors in the individual stages.

Age at diagnosis and treatment have a significant prognostic value in this population $(\mathrm{p}<0.001)$. Adjusting for these factors, the survival probability in each staging system was estimated using the logistic regression model. Each staging system was found to be significant ( $<<0.0001$ in all cases), except the system of Thurman and Donaldson, ${ }^{10}$ where children aged under 1 year are excluded. In this case age at diagnosis was not significant. Otherwise age at diagnosis has independent prognostic value even when the staging systems are added $(p<0 \cdot 001)$. Thereafter all staging systems were added to the model in a stepwise manner if there was no redundancy, and the system of Evans et $a^{1}{ }^{16}$ was found to have independent prognostic value $(p<0.0001)$, whereas the other staging systems provided no further information. The significance level was set at $0 \cdot 05$.

It is of interest that this study confirms the existence of stage IV-S of Evans et al ${ }^{115}$ with a favourable prognosis among infants with metastatic disease in liver and skin. Only the systems of Sandstedt $e t a l^{7}$ and Cohen ${ }^{8}$ give the same information.

Furthermore, it should be mentioned that the three survivors in stage IV of Evans et al ${ }^{1}$ had involvement of bone or bone marrow, and a prognostic favourable subgroup of stage IV-N with involvement of lymph nodes only ${ }^{16}$ could thus not be identified in this population.

Evaluation of the role of surgical excision of the primary tumour on the prognosis. All patients in stage I of Evans et al $^{16}$ had the primary tumour excised. Seventeen patients had a pT1 operation 
Table Comparison of the different staging systems proposed for neuroblastomas. Values given are stages of each system and survivors/total

\begin{tabular}{|c|c|c|c|c|c|c|c|c|c|c|c|c|}
\hline \multirow{2}{*}{$\begin{array}{l}\text { Evans et al } \\
\text { Stage } \\
\text { I }\end{array}$} & \multicolumn{2}{|c|}{ Evans et al ${ }^{16}$} & Pinkel et $\mathrm{al}^{2} 3$ & \multicolumn{2}{|c|}{$\begin{array}{l}\text { Sandstedt } \\
\text { et } \mathrm{al}^{7}\end{array}$} & $\frac{\text { Cohen }^{8}}{516 / 20}$ & James ${ }^{9}$ & $\begin{array}{l}\text { Thurman and } \\
\text { Donaldson }\end{array}$ & \multicolumn{2}{|c|}{$\begin{array}{l}T N M \text { clinical } \\
\text { stages }^{4}\end{array}$} & \multicolumn{2}{|c|}{$\begin{array}{l}\text { TNM post } \\
\text { surgical stages }^{4}\end{array}$} \\
\hline & I & $16 / 20$ & $\begin{array}{lc}\text { I } & 13 / 17 \\
\text { IIA } & 3 / 3\end{array}$ & A & $16 / 20$ & $516 / 20$ & I $16 / 20$ & $\begin{array}{lc}\text { I } & 10 / 10 \\
\text { II } & 1 / 1\end{array}$ & $\begin{array}{l}\text { I } \\
\text { II } \\
\text { III }\end{array}$ & $\begin{array}{l}5 / 8 \\
8 / 9 \\
3 / 3\end{array}$ & $\begin{array}{l}\text { I } \\
\text { IIIA }\end{array}$ & $\begin{array}{c}13 / 17 \\
3 / 3\end{array}$ \\
\hline II & II & $30 / 49$ & $\begin{array}{lc}\text { I } & 5 / 9 \\
\text { IIA } & 14 / 21 \\
\text { IIB } & 11 / 19\end{array}$ & B & $30 / 49$ & $\begin{array}{ll}5 & 13 / 20 \\
4 & 17 / 29\end{array}$ & $\begin{array}{ll}\text { I } & 20 / 32 \\
\text { II } & 10 / 17\end{array}$ & $\begin{array}{lc}\text { I } & 5 / 9 \\
\text { II } & 10 / 21\end{array}$ & $\begin{array}{l}\text { I } \\
\text { II } \\
\text { III }\end{array}$ & $\begin{array}{r}10 / 14 \\
9 / 16 \\
11 / 19\end{array}$ & $\begin{array}{l}\text { I } \\
\text { II } \\
\text { IIIA } \\
\text { IIIB }\end{array}$ & $\begin{array}{c}1 / 1 \\
4 / 8 \\
14 / 21 \\
11 / 19\end{array}$ \\
\hline III & III & $2 / 35$ & $\begin{array}{ll}\text { IIA } & 1 / 7 \\
\text { IIB } & 0 / 9 \\
\text { IIIA } & 1 / 19\end{array}$ & B & $2 / 35$ & $\begin{array}{ll}5 & 0 / 3 \\
4 & 2 / 32\end{array}$ & $\begin{array}{ll}\text { I } & 1 / 10 \\
\text { II } & 1 / 25\end{array}$ & II $1 / 31$ & $\begin{array}{l}\text { II } \\
\text { III }\end{array}$ & $\begin{array}{l}2 / 3 \\
0 / 32\end{array}$ & $\begin{array}{l}\text { IIIA } \\
\text { IIIB }\end{array}$ & $\begin{array}{l}1 / 7 \\
1 / 28\end{array}$ \\
\hline IV & IV & $1 / 139$ & $\begin{array}{ll}\text { IIIA } & 0 / 36 \\
\text { IIIB } & 1 / 25 \\
\text { IIIC } & 2 / 78\end{array}$ & $\mathrm{C}$ & $3 / 139$ & $\begin{array}{ll}4 & 0 / 36 \\
1 & 3 / 103\end{array}$ & $\begin{array}{ll}\text { III } & 0 / 36 \\
\text { IV } & 3 / 103\end{array}$ & $\begin{array}{ll}\text { III } & 0 / 48 \\
\text { IV } & 1 / 69\end{array}$ & $\begin{array}{l}\text { IV } \\
\text { V }\end{array}$ & $\begin{array}{l}2 / 132 \\
1 / 7\end{array}$ & $\begin{array}{l}\text { IV } \\
\text { V }\end{array}$ & $\begin{array}{l}2 / 132 \\
1 / 7\end{array}$ \\
\hline
\end{tabular}

performed, of whom four died: one for surgical reasons, one as a result of fatal complications due to chemotherapy, one by homocide, and one (whose tumour was a sacrococcygeal teratoma with areas of neuroblastic tissue among many other types of mature and immature structures) from progressive disease. Three patients had a pT3a operation performed and none died.

In stage II of Evans et al ${ }^{16} 35$ children had the primary tumour excised, by either primary (34 cases) or secondary operations (one case who had a ypT1 operation performed. Histological examination of the tumour at that time, however, revealed only mature ganglioneuroma tissue. The child, who has survived, seems thus not to have had a beneficial effect from surgery.). Of the 34 children who had the tumour excised, 21 survived (survival rate $62 \%$ ) compared with nine of the 15 patients who did not have the tumour excised (including the above mentioned patients who had the secondary operation performed) (survival rate $60 \%$ ). This was not significant. Nine patients had a pT1 operation performed, five of whom survived. Twenty one patients had a pT3a operation performed, of whom 14 survived. Four patients had a pT3b operation performed, two of whom survived. There were no differences in survival between the different types of operation performed.

In stage III of Evans et al ${ }^{16} 16$ children had the primary tumour excised, by either primary (11 cases) or secondary (five) operations, of whom two survived (survival rate $13 \%$ ), compared with none of the 19 children who did not have the tumour excised (not significant). The excisions performed were ypT1 in one case (who died), pT3a in seven (one survivor), ypT3a in one (who died) pT3b in four (no survivors), and ypT3b in three (one survivor). Thus there were no differences in survival between the different types of operation performed.

In stage IV of Evans et al $^{1}{ }^{6} 28$ children had the primary tumour excised, by either primary (20 cases) or secondary (8) operations, of whom two survived (survival rate $7 \%$ ), compared with one of the 111 children who did not have the primary tumour excised (survival rate $1 \%$ ) (not significant). The excisions performed were pT1 in three cases (no survivors), pT3a in four (no survivors), ypT3a in one (who survived), pT3b in 13 cases (no survivors), and ypT3b in seven (one survivor). Again there were no differences in survival between the different types of operation performed.

In stage IV-S of Evans $e t a^{1}$ none of the children had the primary tumour excised at diagnosis, but two children had a secondary operation performed later. The operations performed were ypT0 (as the primary tumour had disappeared) and ypT1, respectively. Both of these children survived, but it is difficult to evaluate the role of surgery in the survival in these cases. Two of the other eight children with stage IV-S disease had survived also.

\section{Discussion}

All the staging systems examined here have prognostic significance for survival when based on a retrospective assignment of the extent of the disease in 253 patients. This finding is not surprising as the systems proposed by the different authors have been based on clinical experience with neuroblastomas. Only the systems of Evans et $a^{1}{ }^{16}$ and Pinkel 
et $a l^{23}$ however, have been evaluated prospectively 61517318 and have proved their validity in predicting the prognosis for survival for the patients in the different staging groups.

For staging purposes investigations not performed have been considered negative in this study. This means that the stage of the disease in the individual patient is the minimum stage. Although radiographic skeletal surveys were only performed in 179 patients, bone marrow aspirates were only performed in 126, and regional lymph nodes were not sampled systematically and when sampled included lymph nodes adjacent to the tumour. ${ }^{18}$ Only the following unperformed investigations may give rise to bias in the distribution of patients between the various stages: Evans' stage I: bone marrow aspirates not done in eight patients, all of whom survived, with only two receiving chemotherapy; Evans' stage II: regional lymph node biopsy examination not performed in eight patients, and bone marrow aspirates not done in 22 , of whom 13 survived, with only two receiving chemotherapy (survival rate 13/22 compared with 17/27 who had bone marrow aspirates performed); Evans' stage III: regional lymph node biopsy examination not performed in six patients, and bone marrow aspirates not performed in eight, of whom one who received chemotherapy survived (survival rate 1/8 compared with 1/27 who had bone marrow aspirates performed). In patients with Evans' stages IV and IV-S disease investigations not performed could not have altered the stage.

Ideally, age should not be an independent prognostic factor in a staging system. We found, however, that age has independent prognostic significance in all staging systems except that of Thurman and Donaldson, ${ }^{10}$ which excludes all children aged under 1 year. This is in accordance with the findings of most other authors. ${ }^{1-36714161920}$

All staging systems investigated except the TNM clinical stage grouping ${ }^{4}$ are based on non-invasive diagnostic methods as well as surgical estimation of the extent of the primary tumour. In the systems proposed by James, ${ }^{9}$ Thurman and Donaldson, ${ }^{10}$ and Pinkel et $a l^{2{ }^{3}}$ and the TNM post surgical histopathological stage grouping system ${ }^{4}$ the resectability of the primary tumour in localised and regional disease is part of the systems, whereas the resectability of the tumour is not a part of the staging systems of Evans et al, ${ }^{16}{ }^{6}$ Sandstedt et al ${ }^{7}$ or Cohen. ${ }^{8}$ The latter authors note only the extent of the disease without reference to resectability. In the systems of Pinkel $e a^{a l^{2}}{ }^{3}$ and the TNM post surgical histopathological stage grouping ${ }^{4}$ even a microscopic evaluation of lymph nodes and the margin of resection in the tumour is included. Based on this surgicopathologic staging system, Hayes et al found that involvement of lymph nodes in localised and regional disease was a poor prognostic feature ${ }^{18}$ in accordance with Ninane $e t a l^{21}$ but contrary to the findings of others. ${ }^{6}{ }^{19}$ In a retrospective analysis Tourneau et al found involvement of regional lymph nodes did not worsen the prognosis if the involved nodes were completely resected ${ }^{20}$ perhaps because all of their patients with positive lymph nodes had subsequent chemotherapy.

Based on this retrospectively staged patient population we found the staging system of Evans $e t$ $a^{1}{ }^{16}$ superior to the other proposed systems tested for in predicting the final outcome for the children. The TNM clinical stage grouping system ${ }^{4}$ in particular seems to be too rough in predicting the prognosis for the children with local and regional disease, as the extent of the tumour is not visualised by operation. The superiority of the system proposed by Evans $\mathrm{et} \mathrm{al}^{16}$ may be due to two factors. Firstly, the determination of crossing or not crossing the midline relates the tumour size to the size of the patient, whereas the measurement of the tumour mass in centimetres did not adjust tumour size for the size of the patient and it is probably the relative tumour bulk that reflects the possibility of micrometastases beside the detectable extent of the tumour. Secondly, the data collected here strongly suggest that factors other than the resectability of the tumour and the completeness of this resection have considerable influence on the prognosis, a finding which to some extent is in accordance with the findings of other authors. ${ }^{1714161922}$

Several authors have suggested the primary role of surgical excision of the tumour for survival. ${ }^{2} 718-202223$ The resectability of the tumour is, however, closely correlated to tumour stage. Thus in stage I of Evans et al ${ }^{1}$ all the tumours were resected, in stage II most tumours were resected, and in stage III only about half of the tumours were resected. In stage IV it seems that the sensitivity of the tumour to irradiation and chemotherapy has the major influence on survival as a 'second look' operation is carried out on those who respond to the other treatment given ${ }^{172024}$ and as resection of the primary tumour at diagnosis did not seem to influence the final outcome. ${ }^{17} 20$ The survival rate for the children in stage III-IV who underwent a 'second look' operation was $3 / 13$ in this study, a figure that did not differ significantly from the survival rate of $7 / 10$ reported by Grosfeld et al. ${ }^{24}$

\section{Conclusion}

In an unselected patient population the staging system proposed by Evans et al $^{1}$ was found to be 
superior to other systems, including the recently proposed TNM system. ${ }^{4}$ This seems to be due to the fact that factors other than the resectability of the tumour play a major role in survival. Another reason could be that the tumour size in the system of Evans et $a l^{1}$ is related to the size of the patient, whereas the TNM clinical stage grouping system $^{4}$ did not adjust tumour size to the size of the patient.

The result is based, however, on a retrospectively staged patient population, and only a prospective investigation could clarify which staging system is best. In a prospective investigation of the ability of the TNM staging system to predict the final outcome for patients with neuroblastoma, however, the patients should be staged according to the system of Evans $e t a l^{16}$ as well.

We thank the chief physicians at almost all Danish hospitals for placing hospital records at our disposal, with special thanks to the many secretaries who located them in hospital archives.

\section{References}

1 Evans AE, D'Angio GJ, Randolph J. A proposed staging for children with neuroblastoma. Cancer 1971;27:374-8.

2 Pinkel D, Pratt C, Holton C, James D, Wreen E, Hustu HO. Survival of children with neuroblastoma treated with combination chemotherapy. J Pediatr 1968;73:928-31.

${ }^{3}$ Green AA, Hustu HO, Palmer R, Pinkel D. Total-body sequential segmental irradiation and combination chemotherapy for children with disseminated neuroblastoma. Cancer 1976;38:2250-7.

${ }^{4}$ Harmer MH, ed. International Union against Cancer: TNM classification of malignant tumours. 3rd ed. Geneva: International Union against Cancer, 1982;135-46.

5 Carlsen NLT, Schroeder H, Bro PV, et al. Neuroblastomas treated at the four major child oncologic clinics in Denmark 1943-1980: an evaluation of 180 cases. Med Pediatr Oncol 1985;13:180-6.

6 Evans AE, Albo V, D'Angio GJ, et al. Factors influencing survival of children with nonmetastatic neuroblastoma. Cancer 1976;38:661-6.

7 Sandstedt B, Jereb B, Eklund G. Prognostic factors in neuroblastomas. Acta Pathol Microbiol Immunol Scand Sect[A] 1983;91:365-71.
${ }^{8}$ Cohen D. Neuroblastoma: factors affecting survival. $Z$ Kinderchir 1969;6(suppl):389-95.

9 James DH. Proposed classification of neuroblastoma. J Pediatr 1967;71:764.

10 Thurman WG, Donaldson M. Current concept in the management of neuroblastoma. In: Anderson Hospital MD, ed. Neoplasia in childhood. Chicago: Year Book Medical Publishers, 1969:175-81.

11 Beckwith JB, Martin RF. Observations on the histopathology of neuroblastomas. J Pediatr Surg 1968;3:106-10.

12 Beckwith JB, Perrin EV. In situ neuroblastomas: a contribution to the natural history of neural crest tumours. Am J Pathol 1963;43:1089-101.

13 Turkel SB, Itabashi HH. The natural history of neuroblastic cells in the fetal adrenal gland. Am J Pathol 1974;76:225-43.

14 Breslow N, McCann B. Statistical estimation of prognosis for children with neuroblastoma. Cancer Res 1971;31:2098-103.

15 Evans A E, Baum E, Chard R. Do infants with stage IV-S neuroblastoma need treatment? Arch Dis Child 1981;56:271-4.

16 Rosen EM, Cassady JR, Frantz CN, Krestchmar CS, Levey R, Sallen SE. Stage IV-N: a favourable subset of children with metastatic neuroblastoma. Med Pediatr Oncol 1985;13:194-8.

17 Sitarz A, Finklestein J, Grosfeld J, et al. An evaluation of the role of surgery in disseminated neuroblastoma: a report from the Children's Cancer Study Group. J Pediatr Surg 1983; 18:147-51.

18 Hayes FA, Green A, Hustu HO, Kumar M. Surgicopathologic staging of neuroblastoma: prognostic significance of regional lymph node metastases. $J$ Pediatr 1983;102:59-62.

19 Evans AE, D'Angio GJ, Koop CE. The role of multimodal therapy in patients with local and regional neuroblastoma. $J$ Pediatr Surg 1984;19:77-80.

20 Tourneau JN le, Bernard JL, Hendren WH, Carcassonne M. Evaluation of the role of surgery in 130 patients with neuroblastoma. J Pediatr Surg 1985;20:244-9.

${ }^{21}$ Ninane J, Pritchard J, Jones PHM, Mann JR, Malpas JS. Stage II neuroblastoma. Adverse prognostic significance of lymph node involvement. Arch Dis Child 1982;57:438-42.

${ }^{22}$ Koop CE, Johnson DG. Neuroblastoma: an assessment of therapy in reference to staging. J Pediatr Surg 1971;6:595-600.

${ }^{23}$ Hassenbusch S, Kaizer H, White JJ. Prognostic factors in neuroblastic tumors. J Pediatr Surg 1976;11:287-97.

${ }^{24}$ Grosfeld JL, Ballantine TVN, Baehner RL. Experience with "second-look" operations in pediatric solid tumors. J Pediatr Surg 1978;13:275-80.

Correspondence to Dr N L T Carlsen, Department of Paediatric Surgery, Rigshospitalet, 9 Blegdamsuij, DK-2100 Copenhagen $\varnothing$, Denmark.

Received 8 May 1986 